\title{
A Homolog of the Vertebrate Pituitary Adenylate Cyclase- Activating Polypeptide Is Both Necessary and Instructive for the Rapid Formation of Associative Memory in an Invertebrate
}

\author{
Zsolt Pirger, ${ }^{1,2}$ Zita László, ${ }^{1}$ Ildikó Kemenes, ${ }^{2}$ Gábor Tóth, ${ }^{3}$ Dóra Reglődi, ${ }^{4}$ and György Kemenes ${ }^{2}$ \\ ${ }^{1}$ Department of Experimental Zoology, Balaton Limnological Research Institute, Tihany, H-8237, Hungary, ${ }^{2}$ School of Life Sciences, University of Sussex, \\ Brighton BN1 9QG, United Kingdom, ${ }^{3}$ Department of Medical Chemistry, University of Szeged, Szeged, H-6722, Hungary, and ${ }^{4}$ Department of Anatomy, \\ University of Pécs, Pécs, H-7624, Hungary
}

Similar to other invertebrate and vertebrate animals, cAMP-dependent signaling cascades are key components of long-term memory (LTM) formation in the snail Lymnaea stagnalis, an established experimental model for studying evolutionarily conserved molecular mechanisms of long-term associative memory. Although a great deal is already known about the signaling cascades activated by cAMP, the molecules involved in the learning-induced activation of adenylate cyclase (AC) in Lymnaea remained unknown.

Using matrix-assisted laser desorption/ionization time-of-flight mass spectroscopy in combination with biochemical and immunohistochemical methods, recently we have obtained evidence for the existence of a Lymnaea homolog of the vertebrate pituitary adenylate cyclaseactivating polypeptide (PACAP) and for the AC-activating effect of PACAP in the Lymnaea nervous system. Here we first tested the hypothesis that PACAP plays an important role in the formation of robust LTM after single-trial classical food-reward conditioning. Application of the PACAP receptor antagonist PACAP6-38 around the time of single-trial training with amyl acetate and sucrose blocked associative LTM, suggesting that in this "strong" food-reward conditioning paradigm the activation of AC by PACAP was necessary for LTM to form. We found that in a "weak" multitrial food-reward conditioning paradigm, lip touch paired with sucrose, memory formation was also dependent on PACAP. Significantly, systemic application of PACAP at the beginning of multitrial tactile conditioning accelerated the formation of transcriptiondependent memory.

Our findings provide the first evidence to show that in the same nervous system PACAP is both necessary and instructive for fast and robust memory formation after reward classical conditioning.

\section{Introduction}

Pituitary adenylate cyclase-activating polypeptide (PACAP) was first isolated from ovine hypothalamic extracts, based on its ability to stimulate adenylate cyclase (AC) in the pituitary gland (Miyata et al., 1989).

The distribution pattern of the bioactive forms of PACAP (PACAP27 and PACAP38) (Miyata et al., 1990) and their receptors in the CNS as well as the second messenger pathways activated by PACAP receptors (Vaudry et al., 2009) suggested that PACAP was involved in synaptic plasticity. Indeed, PACAP38 has been found to affect both synaptic plasticity and memory processes in a number of previous studies in vertebrates (Roberto and Brunelli, 2000; Telegdy and Kokavszky, 2000; Otto et al., 2001; Sacchetti et al., 2001; Józsa et al., 2005).

PACAP and its receptors are remarkably highly conserved in invertebrates and vertebrates (Vaudry et al., 2009) and are

Received May 3, 2010; revised Aug. 17, 2010; accepted Aug. 17, 2010.

This work was funded by a Medical Research Council (UK) grant (71343) to G.K. and the following grants to D.R. Hungarian Scientific Research Funds (K72592, CNK78480), Scientific Fund of the Hungarian Ministry of Health (278/2009), and a Bolyai Scholarship (Hungary).

Correspondence should be addressed to Prof. György Kemenes, School of Life Sciences, University of Sussex, Brighton BN1 90G, UK. E-mail: G.Kemenes@sussex.ac.uk.

DOI:10.1523/JNEUROSCI.2577-10.2010

Copyright $\odot 2010$ the authors $\quad 0270-6474 / 10 / 3013766-08 \$ 15.00 / 0$ present in the molluscan CNS, such as the central ganglia of the terrestrial snail Helix pomatia (Hernádi et al., 2008) and the pond snail Lymnaea stagnalis (Pirger et al., 2010). Previously, we have found that long-term memory after single-trial classical reward conditioning in Lymnaea requires CAMP-activated protein kinase (PKA) (Michel et al., 2008). Moreover, both the AC activator forskolin and single-trial classical conditioning induce the phosphorylation of the cAMP response element binding protein (CREB) of this mollusk (Ribeiro et al., 2003). These observations together indicated that similar to other systems (Kandel and Abel, 1995; Margulies et al., 2005), activation of AC is a key step in long-term memory (LTM) formation in Lymnaea. However, there was no information available on the molecules involved in the learning-induced activation of AC in Lymnaea. Importantly, we have now demonstrated both the presence and biochemical activity of PACAP and its receptors in the Lymnaea nervous system (Pirger et al., 2010). Here we tested the hypothesis that this recently identified PACAP-like peptide and its receptors in Lymnaea play a role in the formation of LTM after food-reward classical conditioning.

Lymnaea has many advantages for the experimental analysis of molecular pathways involved in associative LTM (Kemenes, 2008). One of these advantages is that when the same food unconditioned stimulus (US), sucrose, is paired with different types of 


\section{A Single-trial chemical classical conditioning}
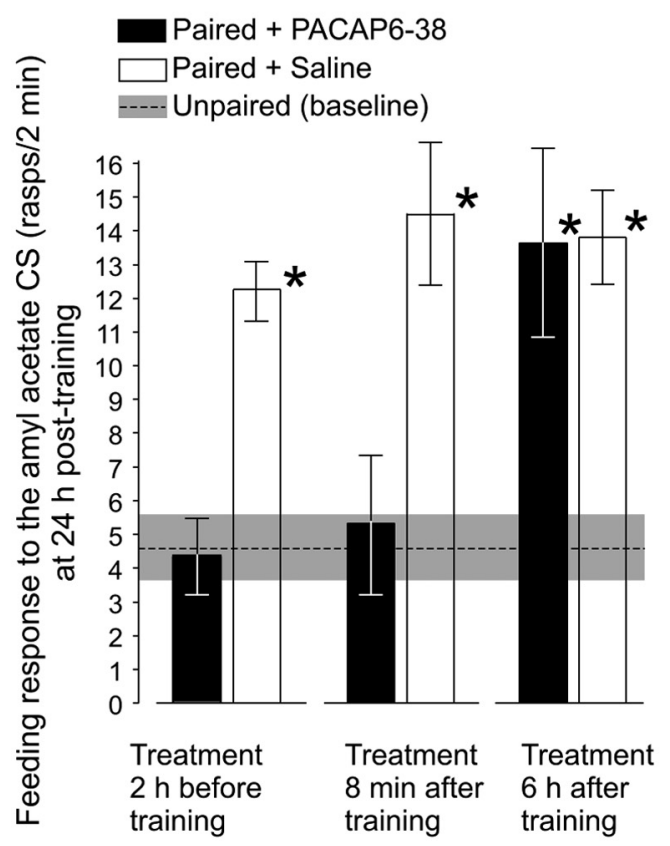

Figure 1. PACAP6-38 blocks the formation of memory after both single-trial chemical (a "strong" training paradigm) and multitrial tactile classical conditioning (a "weak" training paradigm) of feeding. $\boldsymbol{A}$, Application of this PACAP receptor antagonist is effective in blocking memory formation when applied 120 min before or 8 min after single-trial chemical classical conditioning of feeding, but is ineffective when applied at $6 \mathrm{~h}$ after training. The means of the CS-evoked feeding responses and the SEM are shown in this diagram and all subsequent figures. In this figure, the mean baseline feeding response is shown as a dashed line and the SEM of the baseline response is shown as a gray band. Asterisks indicate significant differences from the unpaired baseline level. Test statistics were as follows: one-way ANOVAs: injection 120 min before training, $F_{(2,70)}=23.8, p<0.0001$; Tukey's test between paired + saline and unpaired baseline, $p<$ 0.001; Tukey's test between paired + PACAP6-38 and unpaired baseline, $p>0.05$ (n.s.). Injection 8 min aftertraining, $F_{(2,49)}=13.9, p<$ 0.0001 , Tukey's test between paired + saline and unpaired baseline, $p<0.001$; Tukey's test between paired + PACAP6-38 and unpaired baseline, $p>0.05$ (n.s.). Injection $6 \mathrm{~h}$ after training, $F_{(2,52)}=16.3$; Tukey's test between paired + saline and unpaired baseline, $p<$ 0.001; Tukey's test between paired + PACAP6-38 and unpaired baseline, $p<0.001$. B, PACAP6-38 is also effective in blocking memory formation after multitrial tactile classical conditioning of feeding. The responses are calculated as differences between the spontaneous rasping rates in water and the rasping rates after the delivery of the conditioned stimulus. Without training, lip touch has a mild inhibitory effect on spontaneous rasping (Kemenes and Benjamin, 1989), so in the case of tactile stimulation, the rates after the application of the stimulus can also take negative values (also see Figs. $2-5$ ). Test statistics were as follows: one-way ANOVA, $F_{(2,57)}=8.9, p<0.0004$; Tukey's test between paired + saline and unpaired baseline, $p<0.01$; Tukey's sestbetween paired + PACAP6-38 and unpaired baseline, $p>0.05$ (n.s.). Asterisks indicate significant differences from the unpaired baseline level.

conditioned stimuli (CSs), classical conditioning results in either fast or slow food-reward learning. Thus, pairing amyl acetate with sucrose leads to LTM after a single trial (Alexander et al., 1984), whereas pairing lip touch with sucrose leads to LTM only after $>6$ trials (Kemenes and Benjamin, 1989). The availability of both a "strong" and a "weak" food-reward conditioning paradigm allowed us to perform both "loss of function" and "gain of function" type experiments in the same system. Here we used these food-reward conditioning paradigms to answer questions about both the necessity for PACAP for fast-forming LTM after single-trial chemical conditioning and whether or not it could boost LTM formation when applied in conjunction with multiple-trial tactile conditioning.

\section{Materials and Methods}

Experimental animals. Lymnaea stagnalis pond snails were bred at the University of Sussex. The snails, which are hermaphroditic, were maintained in large holding tanks filled with $\mathrm{Cu}^{2+}$-free water (also used throughout the experiments) at $18-20^{\circ} \mathrm{C}$ with a $12 \mathrm{~h}$ light-dark cycle, and fed ad libitum on lettuce and a vegetable-based fish food (TETRA
Werke). The animals were food deprived for $2 \mathrm{~d}$ before the beginning of the conditioning procedure.

Single-trial chemical classical conditioning. In this "strong" training paradigm, snails were trained using an established single-trial reward classical conditioning protocol (Alexander et al., 1984; Kemenes et al., 2002), which is based on pairing a chemical CS with a food US. Before training, the snails were placed individually into Petri dishes containing $90 \mathrm{ml}$ of water for a $10 \mathrm{~min}$ acclimatization period, so that a constant low level of spontaneous rasping (stereotyped feeding movements of the mouth) was reached in the novel environment (Kemenes and Benjamin, 1994). For classical conditioning, $5 \mathrm{ml}$ of amyl acetate solution $(0.08 \%$ in water, the CS $)$ was delivered into the dish using a plastic syringe and was followed $15 \mathrm{~s}$ later by $5 \mathrm{ml}$ of sucrose solution $(13.4 \%$ in water, the US). Snails remained in the CS + US mixture for a further $105 \mathrm{~s}$ (thus the total time exposed to stimuli was $2 \mathrm{~min}$ ). For unpaired training, snails were presented with the CS and the US with a $1 \mathrm{~h}$ interstimulus interval. After paired or unpaired training, the snails were placed into a tank of clean water and after 10 min transferred back to their home tanks. For testing, individual snails were taken from their home tanks using a blind procedure and placed in Petri dishes. After a 10 min acclimatization period, rasps were counted for 2 min (i.e., spontaneous rasping in the absence of the CS). Five milliliters of the CS were then applied to the dish, and rasps were counted for a further 2 min (i.e., rasping in the presence of the CS). The feeding response to the CS was defined as the number of rasps in the presence of CS minus the number of spontaneous rasps.

Multiple-trial tactile classical conditioning. In this "weak" paradigm, snails were trained using an established multiple-trial reward classical conditioning protocol (Kemenes and Benjamin, 1989; Staras et al., 1999), which is based on pairing a tactile stimulus to the lips (the CS) with sucrose (the US). The pretraining treatment of the snails in this experiment was the same as described for the chemical conditioning paradigm. During each trial of the spaced tactile classical conditioning, the snails were first presented with a touch to the lips. As the animals were freely moving, the touch stimulus was presented using a hand-held probe with a tip made of a thin wedge of soft, flexible plastic (Staras et al., 1999). The target zone on the lip structure was the median portion adjacent to the mouthparts including the leading edge of the lips as previously described by Staras et al. (1998). Within 1 s of the presentation of the tactile CS, sucrose, the US, was presented (final concentration 13.4\%). The pairing of touch with sucrose constituted one trial. After this, the animals were rinsed in a clean water tank to remove any residual sucrose before they were placed back into the home tank. Ninety minutes after the first trial, the animals received a second training trial followed by a third trial another 90 min later. This procedure was repeated on 3 consecutive days, so each snail received a total of nine pairings of the CS and US in a spaced manner. For explicitly unpaired control, on each day of the experiment snails received three presentations of the CS and US with a 10 min interstimulus interval.

For testing, individual snails were taken from their home tanks using a blind procedure and placed in Petri dishes. After a 10 min acclimatization period, rasps were counted for $2 \mathrm{~min}$ (i.e., spontaneous rasping). A touch was then applied to the lips, and rasps were counted for a further $2 \mathrm{~min}$ (i.e., the feeding response to the tactile CS). 
A

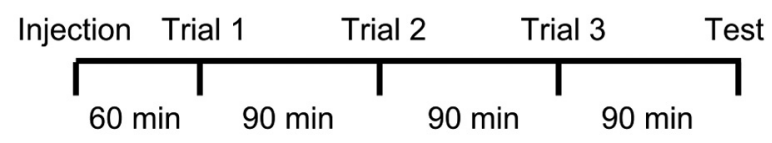

B

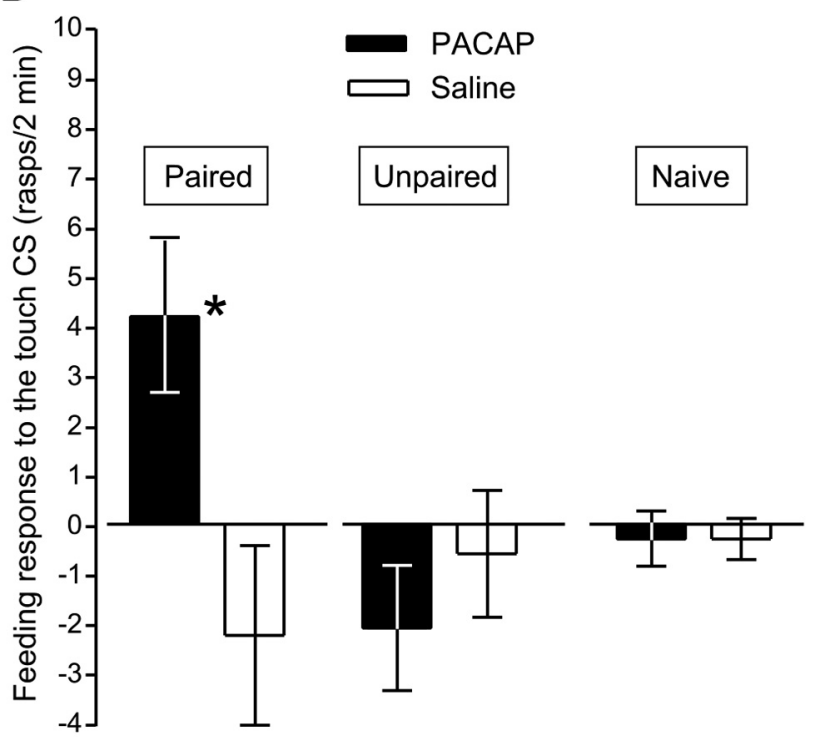

3 trials $+90 \mathrm{~min}$

'3 trials' +90 min

Figure 2. Exogenous PACAP38 boosts associative memory expressed early ( $90 \mathrm{~min}$ ) after multitrial tactile classical conditioning (a "weak" training paradigm). $A$, Timeline of the injection (PACAP or saline), training trials (lip touch + sucrose) and test (lip touch only) protocol. $\boldsymbol{B}$, Feeding responses to the test lip touch in the paired, unpaired and naive group of animals. Test statistics were as follows: two-way ANOVA for interaction, $F_{(2,66)}=4.6, p<0.01$; two-way ANOVA for training and injection, all differences aren.s. $\left(F_{(2,66)}=1.3\right.$ and $1.8, p=0.27$ and 0.18 , respectively). The lack of a significant effect of the training factor means that without PACAP treatment, there is no significant memory expression at 90 min even when the animals have been classically conditioned. The lack of a significant effect of the injection factor, on the other hand, means that PACAP treatment alone does not result in an enhanced feeding response to the CS. Bonferroni's post hoc tests confirmed that, when compared against the effect of saline, PACAP only had a significant effect in the paired group $(t=3.6, p<0.01)$. Unpaired group, $t=0.7, p>0.05$ (n.s.); naive group, $t=0.0, p>0.05$ (n.s.). The asterisk indicates the significant change resulting from the interaction between PACAP treatment and classical conditioning.

Treatment of intact animals with a PACAP receptor antagonist or $P A C A P$ and with PACAP and actinomycin-D. As part of the single-trial chemical classical conditioning experiments, groups of trained animals were treated with the PACAP receptor inhibitor PACAP6-38 (0.6 $\mu \mathrm{m}$ final concentration) or saline either $120 \mathrm{~min}$ before or $8 \mathrm{~min}$ or $6 \mathrm{~h}$ after training.

As part of the multitrial tactile classical conditioning experiments, groups of trained as well as naive and unpaired control animals were injected with PACAP38 (1.1 $\mu \mathrm{M}$ final concentration) or saline $60 \mathrm{~min}$ before the first trial. In one experiment, groups of trained animals were injected with either PACAP38 (1.1 $\mu \mathrm{M}$ final concentration) or saline 60 min before the first trial or with PACAP38 60 min before training followed by injection of PACAP6-38 (2.5 $\mu \mathrm{M}$ final concentration) or saline at $8 \mathrm{~min}$ after the first trial. In another type of experiment, groups of trained animals were injected with PACAP6-38 (2.5 $\mu \mathrm{M}$ final concentration) or saline at $8 \mathrm{~min}$ after the first trial, without pretreating the same animals with PACAP38. In a final type of experiment using multitrial classical conditioning, groups of trained animals were injected with a mixture of PACAP and actinomycin-D (Act-D), a transcriptional blocker, or PACAP or saline $60 \mathrm{~min}$ before the first trial, and the animals were tested for memory $90 \mathrm{~min}$ and $18 \mathrm{~h}$ after three training trials. Drug treatments were performed using previously published methods (Kemenes et al., 2002; Fulton et al., 2005).
Statistical methods. After appropriate tests were run to verify that the data collected from the experiments were normally distributed, we used parametric statistical methods to assess significance levels.

Pretreatment and posttreatment differences within the same groups were analyzed by paired $t$ tests. Differences between two independent groups were analyzed by unpaired $t$ tests.

Multiple comparisons were made by one-way ANOVA followed by Tukey's post hoc tests to determine pairwise differences among the groups used in the experiment.

Two-way ANOVAs were used to analyze interactions between the type of behavioral treatment (paired or unpaired training) and pharmacological treatment (drug or vehicle) used in the experiments. Bonferroni's post hoc tests were used to determine the sources of significant effects revealed by the two-way ANOVA. Differences were considered significant at $p<0.05$. All statistical analyses were performed using GraphPad Prism.

Peptide synthesis. PACAP38 and PACAP6-38 were synthesized in the Department of Medical Chemistry, University of Szeged, which has specialist industry-standard expertise in synthesizing peptides. It has all the necessary infrastructure and expert knowledge to prepare a large variety of different peptides. Every peptide synthesized in this department undergoes rigorous quality control based on HPLC techniques and sequence analysis using electrospray ionization mass spectrometry techniques. Another important reason for synthesizing PACAP38 and PACAP6-38 in-house was that these peptides have been successfully used in our previous work (Pirger et al., 2010) to demonstrate that PACAP and its receptors are present and biochemically active in the CNS of Lymnaea, independent of any behavioral assays.

The synthesis of PACAP38 and PACAP6-38 was performed using a solid-phase procedure using ${ }^{\mathrm{t}} \mathrm{Boc}$ chemistry. Peptide chains were elongated on a 4-methylbenzhydrylamine resin $(0.48 \mathrm{mmol} / \mathrm{g})$, and the synthesis was performed using an ABI 430 machine. Coupling steps were monitored using quantitative ninhydrin tests. Crude peptides were purified by reverse-phase HPLC (RP-HPLC) using Nucleosil C18 columns. Collected fractions corresponding to PACAP were pooled and lyophilized (purity $>98 \%$ ) and analyzed using analytical RP-HPLC and matrix-assisted laser desorption/ionization time-of-flight (MALDITOF) mass spectrometry.

\section{Results}

In Lymnaea, food-reward classical conditioning with amyl acetate (CS) and sucrose (US) works with just a single trial (Alexander et al., 1984). In contrast, food-reward classical conditioning with lip touch as the CS and sucrose as the US is a "weak" paradigm, leading to robust LTM only after 6-10 spaced trials (Kemenes and Benjamin, 1989; Staras et al., 1998). The availability of both a "strong" and a "weak" food-reward conditioning paradigm in the same system provided us with an opportunity to test whether or not PACAP was required for memory formation after the two different types of classical conditioning procedures. Importantly, the availability of the multitrial tactile conditioning paradigm also provided us with an opportunity to test whether or not treatment with PACAP can boost memory formation during this "weak" paradigm.

The PACAP receptor antagonist PACAP6-38 inhibits memory formation after both single-trial chemical and multitrial tactile food-reward conditioning

We used PACAP6-38 to test the hypothesis that the recently identified endogenous Lymnaea PACAP (Pirger et al., 2010) plays an important role in the early physiological processes of memory formation after food-reward conditioning.

First, in an experiment conducted on 10 animals, we established that treatment with PACAP6-38 (0.6 $\mu \mathrm{M}$ final concentration) has no significant effect on the feeding response to sucrose, the US, at the time of training (feeding score 120 min before 


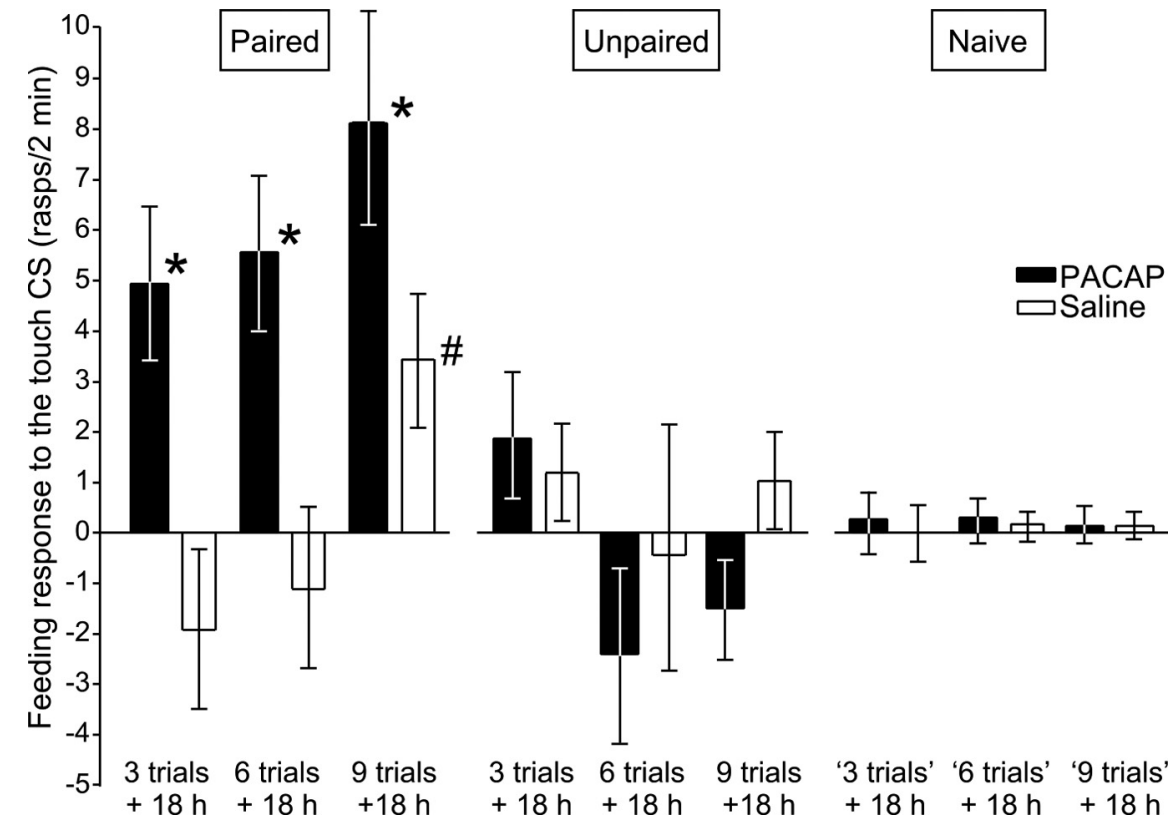

Figure 3. Exogenous PACAP38 boosts memory expressed late (18 h) after multitrial tactile classical conditioning. The injection and training protocol on each of the $3 \mathrm{~d}$ of the experiment was the same as that shown in Figure $2 A$, but the test (lip touch only) was performed $18 \mathrm{~h}$ after the last trial. The graphs show the feeding responses to the test lip touch in paired and unpaired groups of animals after increasing numbers of trials or at corresponding time points in the naive control group (indicated by the number of trials shown between inverted commas). Test statistics were as follows: two-way ANOVA for interaction, 3 trials $+18 \mathrm{~h}, F_{(2,66)}=5.6, p<0.005,6$ trials $+18 \mathrm{~h}, F_{(2,66)}=4.7, p<0.01,9$ trials $+18 \mathrm{~h}, F_{(2,64)}=3.9, p<0.02$; two-way ANOVA for training, 3 trials $+18 \mathrm{~h}$ and 6 trials $+18 \mathrm{~h}, F_{(2,66)}=1.3$ and $1.9, p=0.27$ and 0.14 , respectively (n.s.), 9 trials $+18 \mathrm{~h}$, $F_{(2,64)}=13.6, p<0.0001$; two-way ANOVA for injection, all differences are n.s. ( 3 trials, $F_{(2,66)}=1.8, p=0.18 ; 6$ trials, $F_{(2,66)}=$ $1.5, p=0.22 ; 9$ trials, $\left.F_{(2,64)}=0.7, p=0.39\right)$. The lack of a significant effect of the training factor in the experiments with 3 and 6 trials means that without PACAP treatment, there is no significant memory expression at $18 \mathrm{~h}$ even when the animals have been classically conditioned. The lack of a significant effect of the injection factor in all three experiments $(3,6$, and 9 trials) means that PACAP treatment alone does not result in an enhanced feeding response to the $C S$. Bonferroni's posthoctests confirmed that, when compared against the effect of saline, PACAP only had a significant effect in the paired groups ( 3 trials, $t=3.8, p<0.01 ; 6$ trials, $t=3.5, p<0.01 ; 9$ trials, $t=2.9, p<0.05$ ). Unpaired groups, 3 trials, $t=0.8, p>0.05$ (n.s.); 6 trials, $t=0.8, p>0.05$ (n.s.); 9 trials, $t=1.09, p>0.05$ (n.s.). Naive groups, "3 trials", $t=0.2, p>0.05$ (n.s.); "6 trials", $t=0.1, p>0.05$ (n.s.); "9 trials", $t=$ $0.0, p>0.05$ (n.s.). Asterisks indicate significant changes resulting from the interaction between PACAP treatment and classical conditioning. The hash symbol indicates the significant effect arising solely from classical conditioning after 9 trials. One-way ANOVA, $F_{(2,34)}=6.7, p<0.04$. Tukey's post hoc tests, paired versus unpaired, $p<0.05$; paired versus naive, $p<0.01$; unpaired versus naive, $p>0.05$ (n.s.).

injection, $19.3 \pm 2.3 \mathrm{rasps} / 2 \mathrm{~min}$; feeding score $120 \mathrm{~min}$ after injection, $22.6 \pm 3.4 \mathrm{rasps} / 2 \mathrm{~min}$; paired $t$ test, $\mathrm{df}=9, t=0.86$, $p=0.4$ ).

We then injected groups of intact animals with PACAP6-38 ( $0.6 \mu \mathrm{M}$ final concentration) or saline $120 \mathrm{~min}$ before, $8 \mathrm{~min}$ after, or $6 \mathrm{~h}$ after single-trial classical conditioning and tested the conditioned response to amyl acetate, the CS, $24 \mathrm{~h}$ after training by comparing it against the response level in an unpaired control group (Fig. 1A). These experiments showed that injection with the PACAP receptor antagonist $120 \mathrm{~min}$ before $(n=20)$ or $8 \mathrm{~min}$ after $(n=11)$ training prevented memory formation (CS responses in trained animals at $24 \mathrm{~h}$ after training not significantly different from unpaired control, $n=27)$. However, animals injected with PACAP6-38 $6 \mathrm{~h}$ after training showed no memory impairment at the $24 \mathrm{~h}$ posttraining test (Fig. $1 \mathrm{~A}$ ). Both the saline-injected group $(n=15)$ and the group injected with the PACAP receptor antagonist $(n=11)$ showed significantly higher levels of feeding response to the CS than the unpaired control group. These experiments demonstrated that PACAP-dependent processes play an important role in the acquisition and early consolidation of LTM after single-trial classical conditioning in Lymnaea.
The effect of PACAP6-38 was also tested using the tactile conditioning paradigm. Similar to the amnesic effect of PACAP6-38 on memory after single-trial chemical food-reward classical conditioning, animals treated with the PACAP receptor antagonist before the first trial showed a significant memory impairment after nine trials when compared to salinetreated conditioned animals (Fig. 1B). These experiments demonstrated that in Lymnaea, both the rapid formation (after a single trial) of memory after chemical food-reward conditioning and the much slower formation (after nine trials) of memory after tactile food-reward conditioning are dependent on PACAP around the time of training. However, the use of the "weak" tactile conditioning paradigm also allowed us to test the effect of exogenous PACAP on memory formation.

\section{PACAP accelerates memory formation} during multiple-trial tactile food-reward conditioning

Three different groups of animals were used in this experiment. In the main experimental group ("paired group”), animals were injected with PACAP38 or saline $60 \mathrm{~min}$ before three training trials with the lip-touch CS and sucrose US (interstimulus interval $<1 \mathrm{~s}$ ) given at $90 \mathrm{~min}$ intertrial intervals (Fig. $2 \mathrm{~A}$ ). On each of 2 further days following the first day of training, three more trials were given. All animals were first tested with the liptouch CS alone 90 min after the third trial (Fig. 2A). Memory tests also were performed $18 \mathrm{~h}$ after three, six, and nine trials. In the main control group ("explicitly unpaired group"), the treatment and test regime was the same as in the paired group and the total number of trials was also the same $(3 \times 3)$, but the CS and US were separated by a $10 \mathrm{~min}$ interval (as opposed to the $<1 \mathrm{~s}$ interval used in the paired group). In a second control group ("naive group"), animals were injected with PACAP38 or saline and then tested with lip touch at the same time intervals as the animals in the two other groups. The use of these three different groups allowed us to establish whether or not PACAP affected the process of associative learning itself rather than either changing the animals' response to the lip touch as a result of nonassociative processes triggered by the CS or US (explicitly unpaired group) or simply enhancing it even in the absence of these stimuli (naive group).

These experiments revealed a significant enhancement of the conditioned feeding response to touch in the paired group that had been pretreated with PACAP38 compared to salinetreated animals also subjected to paired training. Exogenous PACAP enhanced both the $90 \mathrm{~min}$ (Fig. 2 B) and $18 \mathrm{~h}$ (Fig. 3) memory after as few as three trials and induced a significant progressive increase in $18 \mathrm{~h}$ memory in conjunction with increasing numbers of training trials (Fig. 3). Importantly, PACAP treatment did not enhance the feeding response to lip 


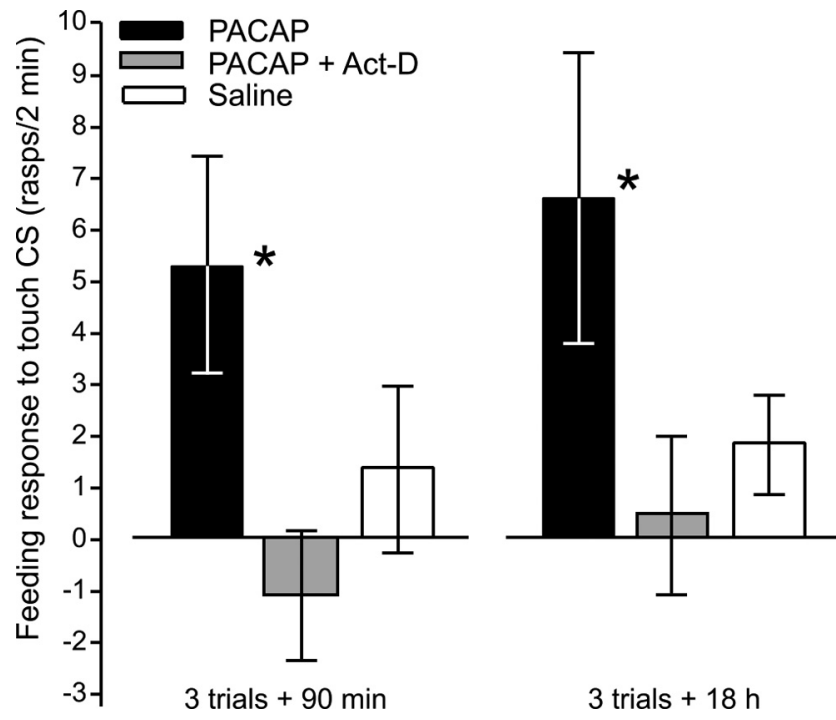

Figure 4. Both the early and late memory-boosting effects of exogenously applied PACAP38 are blocked by actinomycin-D. Memory tests were performed at $90 \mathrm{~min}$ and $18 \mathrm{~h}$ after 3 trials. Test statistics were as follows: 90 min test, one-way ANOVA $F_{(2,50)}=17.5, p<0.0001$; Tukey's (PACAP vs both PACAP + Act-D and saline), $p<0.001$. 18 htest, one-way ANOVAF $F_{(2,50)}=4.1$, $p<0.02$; Tukey's (PACAP + saline versus both PACAP + Act-D and saline), $p<0.05$.

touch in animals of the unpaired and naive control groups either in the shorter (90 min) (Fig. 2A) or longer (18 h) (Fig. 3) term, indicating that PACAP alone is not sufficient for the enhancement of the response, it only works in conjunction with classical conditioning (i.e., it is instructive for memory formation).

The importance of the interaction between PACAP treatment and associative training for the observed memory enhancement was tested by two-way ANOVAs, where the first factor was training (paired, unpaired, or naive) and the second factor was injection (PACAP or vehicle). These statistical tests revealed a significant interaction between PACAP treatment and associative training in both the $90 \mathrm{~min}$ (Fig. 2) and $18 \mathrm{~h}$ (Fig. 3) memory tests but no significant effects for either training or injection alone, except when, $18 \mathrm{~h}$ after nine trials, the saline-injected trained animals too started showing long-term memory (Fig. 3). In each case, Bonferroni's post hoc tests confirmed that only in the paired group did PACAP have a significant effect on the posttraining feeding response to touch (Figs. 2, 3).

The detection of enhanced memory as early as 90 min after three trials in the PACAP-treated animals raised the important question of whether this PACAP-boosted early memory trace was dependent on gene transcription and could therefore be regarded as long-term memory. We therefore performed a new set of experiments that demonstrated that treatment of animals with actinomycin-D significantly impaired the formation of PACAPboosted memory tested at $90 \mathrm{~min}$, as well as $18 \mathrm{~h}$ after three trials (Fig. 4).

\section{The memory-boosting effect of exogenous PACAP is mediated by an endogenous PACAP receptor in the Lymnaea nervous system}

The single-trial and multitrial conditioning and PACAP6-38 injection experiments strongly indicated that binding of an endogenous PACAP-like peptide to a PACAP receptor is necessary for LTM, and the multitrial experiments also showed that exogenously boosting PACAP levels boosts memory formation. How-

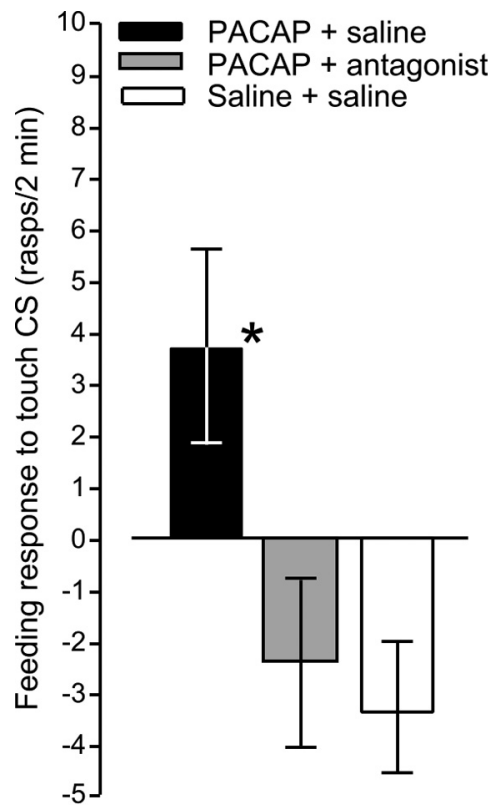

3 trials $+90 \mathrm{~min}$

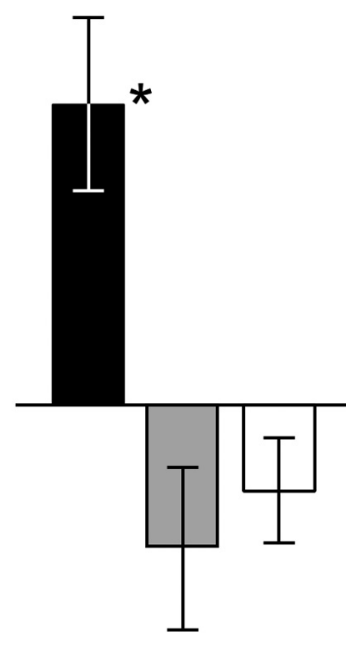

3 trials $+18 \mathrm{~h}$
Figure 5. The memory-boosting effects of exogenously applied PACAP38 are blocked by the PACAP receptor antagonist PACAP6-38. Memory tests were performed at $90 \mathrm{~min}$ and $18 \mathrm{~h}$ after 3 trials. Test statistics were as follows: 90 min test, one-way ANOVA $F_{(2,38)}=6.5, p<0.004$, Tukey's (PACAP + saline versus both PACAP + antagonist and saline + saline), $p<0.05 .18 \mathrm{~h}$ test, one-way ANOVA $F_{(2,38)}=7.6, p<0.002$, Tukey's (PACAP + saline versus both PACAP + antagonist and saline + saline), $p<0.05$.

ever, it was important to elucidate whether or not exogenously applied PACAP affected memory formation by binding to these putative endogenous PACAP receptors. Therefore in a final experiment, we injected trained animals with PACAP6-38 $(2.5 \mu \mathrm{M}$ final concentration) $8 \mathrm{~min}$ after the first trial and following injection with PACAP (1.1 $\mu \mathrm{M}$ final concentration) 60 min before training. Both short-term and long-term conditioned responses were tested after three trials and compared with responses in trained groups that were injected with PACAP or saline $60 \mathrm{~min}$ before training and then with saline $8 \mathrm{~min}$ after the first trial.

Both the $90 \mathrm{~min}$ and $18 \mathrm{~h}$ posttraining memory boosting effect of exogenous PACAP was abolished when application of PACAP before training was followed by application of PACAP6-38 after the first training trial (Fig. 5). This finding provides strong support to the notion that the memory boosting effect of PACAP is mediated by an endogenous vertebrate-like PACAP receptor in the nervous system of Lymnaea.

\section{Discussion}

In this work, we have identified PACAP as an important polypeptide involved in the acquisition and early consolidation of associative LTM after single-trial chemical and multitrial tactile food-reward classical conditioning in Lymnaea. Importantly, we also have shown that systemic application of exogenous vertebrate PACAP accelerates the formation of transcriptiondependent memory during multitrial classical conditioning and this effect is dependent on PACAP binding to PAC1-like receptors endogenous to the Lymnaea nervous system.

Previous behavioral studies in vertebrates already have found that PACAP was necessary for memory formation after certain learning tasks [formation of olfactory memory in the chick (Józsa et al., 2005)] and its systemic application could improve learning and memory [avoidance conditioning in the rat (Telegdy and 


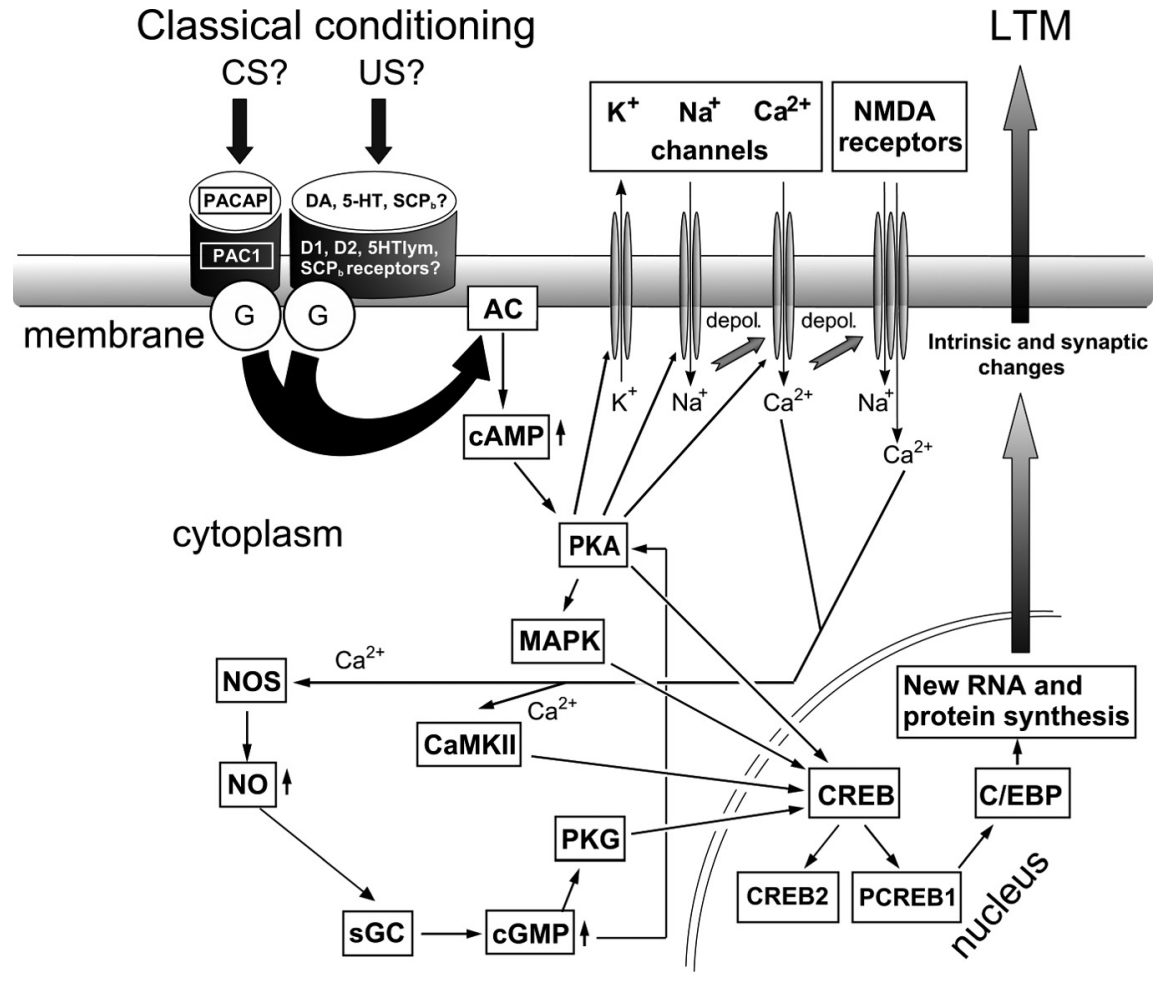

Figure 6. Aschematic representation of the signaling molecules, receptors, ion channels, and pathways involved in memory formation after food-reward classical conditioning in Lymnaea. Molecular components examined in the present study (PACAP, PAC1) as well as those identified in previous reports [AC, Pirger et al. (2010); C/EBP, Hatakeyama et al. (2004); CaMKIl and NMDA, Wan et al. (2010); CAMP, Nikitin et al. (2006); CREB, Ribeiro et al. (2003) and Sadamoto et al. (2004); MAPK, Ribeiro et al. (2005); $\mathrm{Na}^{+}, \mathrm{Ca}^{2+}$, and K ${ }^{+}$channels, Staras et al. (2002) and Nikitin et al. (2008); NOS and NO, Kemenes et al. (2002) and Korneev et al. (2005); PKA, G. Kemenes et al. (2006); RNA and protein synthesis, Fulton et al. (2005); SGC, Ribeiro et al. (2008) and Michel et al. (2008)], are shown boxed. G, G-Protein; DA, dopamine; 5-HT, serotonin;MAPK, mitogen-activated protein kinase; CaMKII, calcium/calmodulin-dependent kinasell; NOS, nitric oxide synthase; NO, nitric oxide; $5 G C$, soluble guanylyl cyclase; PKG, CGMP-activated protein kinase; PCREB, phosphorylated CAMP response element-binding protein; C/EBP, CCAAT enhancer-binding protein.

Kokavszky, 2000; Sacchetti et al., 2001)]. In Drosophila, the famous amnesiac gene encodes a homolog of vertebrate PACAP, and it is strongly expressed in dorsal paired medial neurons, which are required for stable memory (Waddell et al., 2000). Our new work, however, is the first to show that PACAP is both necessary and instructive for fast and robust memory formation after classical conditioning in the same organism. Moreover, our work is the first to directly demonstrate important roles for PACAP in learning and memory in an invertebrate animal, indicating that these roles emerged early in coelomate evolution.

Previously, we have presented biochemical evidence for the ACactivating effect of PACAP in Lymnaea CNS homogenates and MALDI-TOF evidence for the existence of Lymnaea PACAP peptides highly homologous to their vertebrate counterparts (Pirger et al., 2010). We also have provided immunohistochemical evidence for the presence of PACAP in the lip sensory epithelium, lip nerves, and cerebral ganglia (Pirger et al., 2010), and now we also have shown a role for PACAP in learning and early memory consolidation in intact Lymnaea. These four types of experiments together provide comprehensive evidence for both the existence of PACAP in the Lymnaea peripheral nervous system and CNS and its function in associative behavioral plasticity. The immunohistochemical tests that showed abundant PACAP expression in afferent fibers of the lip to cerebral ganglion chemosensory pathways and in the cerebral neuropile (Pirger et al., 2010) lent further strong support to the notion that PACAP plays a role in processes of sensory integration, which are important components of foodreward learning.

\section{A model of the PACAP-activated molecular cascades of memory formation after food-reward classical conditioning in Lymnaea}

Previous molecular, behavioral, pharmacological, and electrophysiological analyses already have identified a number of receptors, ion channels, and signaling molecules involved in the acquisition as well as early and/or late consolidation of associative LTM after food-reward classical conditioning in Lymnaea (Kemenes et al., 2002; Ribeiro et al., 2003, 2005, 2008; Fulton et al., 2005; Korneev et al., 2005; G. Kemenes et al., 2006; Michel et al., 2008; Nikitin et al., 2008; Wan et al., 2010). Our new findings have now made it possible to construct a model of the interacting components involved in the formation of long-term associative memory after foodreward classical conditioning in Lymnaea (Fig. 6). With regards to the role of PACAP, the most important of these components are PKA, MAPK, NOS/NO, CaMKII, and NMDA receptors (Fig. 6). The activation of these molecules is necessary for early consolidation of long-term memory (Kemenes et al., 2002; Ribeiro et al., 2005; Michel et al., 2008; Wan et al., 2010), and all of them can be linked, either directly or indirectly, to the initial activation of AC (Fig. 6).

A number of previous studies in vertebrates have shown that the cAMP/PKA system and the NOS/NO/ cGMP/PKG systems are activated in parallel and make distinct contributions to long-term memory (Quevedo et al., 1997) and its cellular correlates, such as LTP (Lu et al., 1999; Jacoby et al., 2001; Lu and Hawkins, 2002). Our previous work (Kemenes et al., 2002; Michel et al., 2008) suggests a similar parallel role for PKA and NO in LTM after single-trial classical conditioning in Lymnaea, and our new work now suggests that a PACAPmediated activation of AC underlies the activation of PKA by cAMP (Fig. 6).

PACAP-mediated activation of AC is also known to be involved in PKA-mediated activation of voltage-sensitive calcium channels in both vertebrates (Wong et al., 2005) and invertebrates (Bhattacharya et al., 2004) and resulting calcium influx, which may underlie the activation of NOS and CaMKII (Fig. 6). Recent work by others has shown that PACAP is involved in the PKA-mediated activation of NMDA receptors in the hippocampus (Yaka et al., 2003; Macdonald et al., 2005). Previous work in our laboratory and by others has shown that activation of NMDA receptors is necessary for the formation of associative LTM in invertebrates [Aplysia, Murphy and Glanzman (1999); Drosophila, Xia et al. (2005); Lymnaea, Jami et al. (2007), Wu et al. (2007), and Wan et al. (2010)], and we now hypothesize that invertebrate PACAP-like peptides play a mechanistic role in the learninginduced activation of NMDA receptors similar to that previously described in the hippocampus. 
Using in vitro analogs of learning (e.g., heterosynaptic facilitation in Aplysia), PKA was shown to be activated by cAMP (Bacskai et al., 1993; Müller and Carew, 1998; Chain et al., 1999; Lee et al., 2009), but work in insects has demonstrated a strong link between NO/cGMP and cAMP-independent activation of PKA during the formation of behavioral associative memory (Müller, 2000; Matsumoto et al., 2009). This cGMP-mediated PKA activation occurs in the absence of sufficient levels of cAMP, so we can speculate that when endogenous or exogenous PACAP activates AC in Lymnaea during learning, the role for NO/cGMP in direct activation of PKA is negligible. However, in the absence of exogenously applied PACAP38, the NO/cGMP-dependent activation of PKA may be predominant during multitrial tactile conditioning in Lymnaea, making this paradigm similar to multitrial olfactory conditioning in the honeybee (Müller, 2000). Interestingly, when cAMP was directly released by flash photolysis in conjunction with single-trial olfactory conditioning in the honeybee (Müller, 2000), this had an accelerating effect on the formation of LTM, similar to that observed in our experiments after the application of PACAP38.

Adenylate cyclase-activating neuropeptides other than PACAP already have been shown to play important roles in in vitro analogs of learning in Aplysia. The endogenous small cardioactive peptides $\mathrm{SCP}_{\mathrm{A}}$ and $\mathrm{SCP}_{\mathrm{B}}$ of Aplysia were shown to modulate the gill and siphon withdrawal reflex by presynaptic facilitation involving a cAMP-dependent mechanism (Abrams et al., 1984). Activation of AC by the cardioactive peptides and serotonin occurs in parallel, the former being more involved in the facilitation of polysynaptic pathways and the latter having a stronger effect on monosynaptic pathways (Trudeau and Castellucci, 1992) of the gill-siphon withdrawal reflex. Although close homologs of the Aplysia $\mathrm{SCP}_{\mathrm{A}}$ and $\mathrm{SCP}_{\mathrm{B}}$ exist in Lymnaea (Perry et al., 1999), the role of these peptides or 5-HT in memory formation after foodreward conditioning has not yet been investigated in Lymnaea. However, we cannot rule out that similar to Aplysia, several peptide and nonpeptide transmitter and modulator molecules are also capable of activating AC via different G-protein-coupled receptors (Fig. 6).

Pretraining application of PACAP6-38 resulted in a complete abolition of memory after both single-trial chemical and multitrial tactile conditioning (Fig. 1) but not in a loss of the unconditioned feeding response. Based on this finding, it is tempting to speculate that PACAP is released in response to the chemical and tactile conditioned stimuli, whereas similar to what was found in Aplysia, the effect of the unconditioned stimulus on AC may be mediated by different peptide or nonpeptide transmitters, such as SCPs or 5-HT (Trudeau and Castellucci, 1992) or DA (Nargeot et al., 1999; Brembs et al., 2002). We hypothesize that in Lymnaea, the PACAP-mediated effect of the chemical or tactile CS and the non-PACAP mediated effect of sucrose US converge on AC (Fig. 6 ), and this convergence provides the molecular basis for coincidence detection, a fundamental requirement for associative learning. Lymnaea is known to differentiate learning with amyl acetate (I. Kemenes et al., 2006) from learning with touch (Jones et al., 2003) at the neuronal level within the same network (the feeding circuitry), but there is no evidence for a similar differentiation at the molecular level within the same neuron. Thus, the same molecules (e.g., PACAP) can fulfill the same role (e.g., activation of $\mathrm{AC}$ ) in different neurons, leading to learning-induced changes in a variety of different pathways (e.g., activated by touch vs activated by amyl acetate).

\section{References}

Abrams TW, Castellucci VF, Camardo JS, Kandel ER, Lloyd PE (1984) Two endogenous neuropeptides modulate the gill and siphon withdrawal reflex in Aplysia by presynaptic facilitation involving cAMP-dependent closure of a serotonin-sensitive potassium channel. Proc Natl Acad Sci U S A 81:7956-7960.

Alexander J Jr, Audesirk TE, Audesirk GJ (1984) One-trial reward learning in the snail Lymnaea stagnalis. J Neurobiol 15:67-72.

Bacskai BJ, Hochner B, Mahaut-Smith M, Adams SR, Kaang BK, Kandel ER, Tsien RY (1993) Spatially resolved dynamics of cAMP and protein kinase A subunits in Aplysia sensory neurons. Science 260:222-266.

Bhattacharya A, Lakhman SS, Singh S (2004) Modulation of L-type calcium channels in Drosophila via a pituitary adenylyl cyclase-activating polypeptide (PACAP)-mediated pathway. J Biol Chem 279:37291-37297.

Brembs B, Lorenzetti FD, Reyes FD, Baxter DA, Byrne JH (2002) Operant reward learning in Aplysia: neuronal correlates and mechanisms. Science 296:1706-1709.

Chain DG, Casadio A, Schacher S, Hegde AN, Valbrun M, Yamamoto N, Goldberg AL, Bartsch D, Kandel ER, Schwartz JH (1999) Mechanisms for generating the autonomous cAMP-dependent protein kinase required for long-term facilitation in Aplysia. Neuron 22:147-156.

Fulton D, Kemenes I, Andrew RJ, Benjamin PR (2005) A single timewindow for protein synthesis-dependent long-term memory formation after one-trial appetitive conditioning. Eur J Neurosci 21:1347-1358.

Hatakeyama D, Fujito Y, Sakakibara M, Ito E (2004) Expression and distribution of the transcription factor CCAAT/enhancer-binding protein in the central nervous system of Lymnaea stagnalis. Cell Tissue Res 318:631-641.

Hernádi L, Pirger Z, Kiss T, Németh J, Mark L, Kiss P, Tamas A, Lubics A, Toth G, Shioda S, Reglodi D (2008) The presence and distribution of pituitary adenylate cyclase activating polypeptide and its receptor in the snail Helix pomatia. Neuroscience 155:387-402.

Jacoby S, Sims RE, Hartell NA (2001) Nitric oxide is required for the induction and heterosynaptic spread of long-term potentiation in rat cerebellar slices. J Physiol 535:825-839.

Jami SA, Wright WG, Glanzman DL (2007) Differential classical conditioning of the gill-withdrawal reflex in Aplysia recruits both NMDA receptordependent enhancement and NMDA receptor-dependent depression of the reflex. J Neurosci 27:3064-3068.

Jones NG, Kemenes I, Kemenes G, Benjamin PR (2003) A persistent cellular change in a single modulatory neuron contributes to associative longterm memory. Curr Biol 13:1064-1069.

Józsa R, Hollósy T, Tamás A, Tóth G, Lengvári I, Reglodi D (2005) Pituitary adenylate cyclase activating polypeptide plays a role in olfactory memory formation in chicken. Peptides 26:2344-2350.

Kandel E, Abel T (1995) Neuropeptides, adenylyl cyclase, and memory storage. Science 268:825-826.

Kemenes G (2008) Molecular mechanism of associative learning in Lymnaea. In: Learning and memory: a comprehensive reference (Byrne J, ed), Vol 4, Molecular mechanism of memory (Sweatt JD, ed), pp 133-148. Oxford: Elsevier.

Kemenes G, Benjamin PR (1989) Appetitive learning in snails shows characteristics of conditioning in vertebrates. Brain Res 489:163-166.

Kemenes G, Benjamin PR (1994) Training in a novel environment improves the appetitive learning performance of the snail, Lymnaea stagnalis. Behav Neural Biol 61:139-149.

Kemenes G, Kemenes I, Michel M, Papp A, Müller U (2006) Phasedependent molecular requirements for memory reconsolidation: differential roles for protein synthesis and protein kinase A activity. J Neurosci 26:6298-6302.

Kemenes I, Kemenes G, Andrew RJ, Benjamin PR, O’Shea M (2002) Critical time-window for NO-cGMP-dependent long-term memory formation after one-trial appetitive conditioning. J Neurosci 22:1414-1425.

Kemenes I, Straub VA, Nikitin ES, Staras K, O’Shea M, Kemenes G, Benjamin PR (2006) Role of delayed nonsynaptic neuronal plasticity in long-term associative memory. Curr Biol 16:1269-1279.

Korneev SA, Straub V, Kemenes I, Korneeva EI, Ott SR, Benjamin PR, O’Shea M (2005) Timed and targeted differential regulation of nitric oxide synthase (NOS) and anti-NOS genes by reward conditioning leading to longterm memory formation. J Neurosci 25:1188-1192.

Lee YS, Choi SL, Lee SH, Kim H, Park H, Lee N, Lee SH, Chae YS, Jang DJ, Kandel ER, Kaang BK (2009) Identification of a serotonin receptor cou- 
pled to adenylyl cyclase involved in learning-related heterosynaptic facilitation in Aplysia. Proc Natl Acad Sci U S A 106:14634-14639.

Lu YF, Hawkins RD (2002) Ryanodine receptors contribute to cGMPinduced late-phase LTP and CREB phosphorylation in the hippocampus. J Neurophysiol 88:1270-1278.

Lu YF, Kandel ER, Hawkins RD (1999) Nitric oxide signaling contributes to late-phase LTP and CREB phosphorylation in the hippocampus. J Neurosci 19:10250-10261.

Macdonald DS, Weerapura M, Beazely MA, Martin L, Czerwinski W, Roder JC, Orser BA, MacDonald JF (2005) Modulation of NMDA receptors by pituitary adenylate cyclase activating peptide in CA1 neurons requires $\mathrm{G}$ alpha q, protein kinase C, and activation of Src. J Neurosci 25: 11374-11384.

Margulies C, Tully T, Dubnau J (2005) Deconstructing memory in Drosophila. Curr Biol 15:R700-R713.

Matsumoto Y, Hatano A, Unoki S, Mizunami M (2009) Stimulation of the cAMP system by the nitric oxide-cGMP system underlying the formation of long-term memory in an insect. Neurosci Lett 467:81-85.

Michel M, Kemenes I, Müller U, Kemenes G (2008) Different phases of long-term memory require distinct temporal patterns of PKA activity after single-trial classical conditioning. Learn Mem 15:694-702.

Miyata A, Arimura A, Dahl RR, Minamino N, Uehara A, Jiang L, Culler MD, Coy DH (1989) Isolation of a novel 38-residue hypothalamic polypeptide which stimulates adenylate cyclase in pituitary cells. Biochem Biophys Res Commun 164:567-574.

Miyata A, Jiang L, Dahl RD, Kitada C, Kubo K, Fujino M, Minamino N, Arimura A (1990) Isolation of a neuropeptide corresponding to the $\mathrm{N}$-terminal 27 residues of the pituitary adenylate cyclase activating polypeptide with 38 residues (PACAP38). Biochem Biophys Res Commun 170:643-648.

Müller U (2000) Prolonged activation of cAMP-dependent protein kinase during conditioning induces long-term memory in honeybees. Neuron 27:159-168.

Müller U, Carew TJ (1998) Serotonin induces temporally and mechanistically distinct phases of persistent PKA activity in Aplysia sensory neurons. Neuron 21:1423-1434.

Murphy GG, Glanzman DL (1999) Cellular analog of differential classical conditioning in Aplysia: disruption by the NMDA receptor antagonist DL-2-amino-5-phosphonovalerate. J Neurosci 19:10595-10602.

Nargeot R, Baxter DA, Patterson GW, Byrne JH (1999) Dopaminergic synapses mediate neuronal changes in an analogue of operant conditioning. J Neurophysiol 81:1983-1987.

Nikitin ES, Kiss T, Staras K, O’Shea M, Benjamin PR, Kemenes G (2006) Persistent sodium current is a target for cAMP-induced neuronal plasticity in a state-setting modulatory interneuron. J Neurophysiol 95:453463.

Nikitin ES, Vavoulis DV, Kemenes I, Marra V, Pirger Z, Michel M, Feng J, O’Shea M, Benjamin PR, Kemenes G (2008) Persistent sodium current is a nonsynaptic substrate for long-term associative memory. Curr Biol 18:1221-1226.

Otto C, Kovalchuk Y, Wolfer DP, Gass P, Martin M, Zuschratter W, Gröne HJ, Kellendonk C, Tronche F, Maldonado R, Lipp HP, Konnerth A, Schütz G (2001) Impairment of mossy fiber long-term potentiation and associative learning in pituitary adenylate cyclase activating polypeptide type I receptor-deficient mice. J Neurosci 21:5520-5527.

Perry SJ, Dobbins AC, Schofield MG, Piper MR, Benjamin PR (1999) Small cardioactive peptide gene: structure, expression and mass spectrometric analysis reveals a complex pattern of co-transmitters in a snail feeding neuron. Eur J Neurosci 11:655-662.

Pirger Z, Laszlo Z, Hiripi L, Toth G, Lubics A, Reglodi D, Kemenes G, Mark L (2010) Pituitary adenylate cyclase activating polypeptide (PACAP) and its receptors are present and biochemically active in the central nervous system of the pond snail Lymnaea stagnalis. J Mol Neurosci. Advance online publication. Retrieved April 16, 2010. doi:10.1007/s12031-010-9361-x.

Quevedo J, Vianna M, Zanatta MS, Roesler R, Izquierdo I, Jerusalinsky D, Quillfeldt JA (1997) Involvement of mechanisms dependent on NMDA receptors, nitric oxide and protein kinase $\mathrm{A}$ in the hippocampus but not in the caudate nucleus in memory. Behav Pharmacol 8:713-717.
Ribeiro MJ, Serfozo Z, Papp A, Kemenes I, O’Shea M, Yin JC, Benjamin PR, Kemenes G (2003) Cyclic AMP response element-binding (CREB)-like proteins in a molluscan brain: cellular localization and learning-induced phosphorylation. Eur J Neurosci 18:1223-1234.

Ribeiro MJ, Schofield MG, Kemenes I, O’Shea M, Kemenes G, Benjamin PR (2005) Activation of MAPK is necessary for long-term memory consolidation following food-reward conditioning. Learn Mem 12:538-545.

Ribeiro M, Straub VA, Schofield M, Picot J, Benjamin PR, O'Shea M, Korneev SA (2008) Characterization of NO-sensitive guanylyl cyclase: expression in an identified interneuron involved in NO-cGMP-dependent memory formation. Eur J Neurosci 28:1157-1165.

Roberto M, Brunelli M (2000) PACAP-38 enhances excitatory synaptic transmission in the rat hippocampal CA1 region. Learn Mem 7:303-311.

Sacchetti B, Lorenzini CA, Baldi E, Bucherelli C, Roberto M, Tassoni G, Brunelli M (2001) Pituitary adenylate cyclase-activating polypeptide hormone (PACAP) at very low dosages improves memory in the rat. Neurobiol Learn Mem 76:1-6.

Sadamoto H, Sato H, Kobayashi S, Murakami J, Aonuma H, Ando H, Fujito Y, Hamano K, Awaji M, Lukowiak K, Urano A, Ito E (2004) CREB in the pond snail Lymnaea stagnalis: cloning, gene expression, and function in identifiable neurons of the central nervous system. J Neurobiol 58: $455-466$.

Staras K, Kemenes G, Benjamin PR (1998) Neurophysiological correlates of unconditioned and conditioned feeding behavior in the pond snail Lymnaea stagnalis. J Neurophysiol 79:3030-3040.

Staras K, Kemenes G, Benjamin PR (1999) Cellular traces of behavioral classical conditioning can be recorded at several specific sites in a simple nervous system. J Neurosci 19:347-357.

Staras K, Gyori J, Kemenes G (2002) Voltage-gated ionic currents in an identified modulatory cell type controlling molluscan feeding. Eur J Neurosci 15:109-119.

Telegdy G, Kokavszky K (2000) The action of pituitary adenylate cyclase activating polypeptide (PACAP) on passive avoidance learning. The role of transmitters. Brain Res 874:194-199.

Trudeau LE, Castellucci VF (1992) Contribution of polysynaptic pathways in the mediation and plasticity of Aplysia gill and siphon withdrawal reflex: evidence for differential modulation. J Neurosci 12:3838-3848.

Vaudry D, Falluel-Morel A, Bourgault S, Basille M, Burel D, Wurtz O, Fournier A, Chow BK, Hashimoto H, Galas L, Vaudry H (2009) Pituitary adenylate cyclase-activating polypeptide and its receptors: 20 years after the discovery. Pharmacol Rev 61:283-357.

Vavoulis DV, Nikitin ES, Kemenes I, Marra V, Feng J, Benjamin PR, Kemenes G (2010) Balanced plasticity and stability of the electrical properties of a molluscan modulatory interneuron after classical conditioning: a computational study. Front Behav Neurosci 4:19.

Waddell S, Armstrong JD, Kitamoto T, Kaiser K, Quinn WG (2000) The amnesiac gene product is expressed in two neurons in the Drosophila brain that are critical for memory. Cell 103:805-813.

Wan H, Mackay B, Iqbal H, Naskar S, Kemenes G (2010) Delayed intrinsic activation of an NMDA-independent CaM-kinase II in a critical time window is necessary for late consolidation of an associative memory. J Neurosci 30:56-63.

Wong AO, Li W, Leung CY, Huo L, Zhou H (2005) Pituitary adenylate cyclase-activating polypeptide (PACAP) as a growth hormone (GH)releasing factor in grass carp. I. Functional coupling of cyclic adenosine 3',5'-monophosphate and Ca2+/calmodulin-dependent signaling pathways in PACAP-induced GH secretion and GH gene expression in grass carp pituitary cells. Endocrinology 146:5407-5424.

Wu CL, Xia S, Fu TF, Wang H, Chen YH, Leong D, Chiang AS, Tully T (2007) Specific requirement of NMDA receptors for long-term memory consolidation in Drosophila ellipsoid body. Nat Neurosci 10:1578-1586.

Xia S, Miyashita T, Fu TF, Lin WY, Wu CL, Pyzocha L, Lin IR, Saitoe M, Tully T, Chiang AS (2005) NMDA receptors mediate olfactory learning and memory in Drosophila. Curr Biol 15:603-615.

Yaka R, He DY, Phamluong K, Ron D (2003) Pituitary adenylate cyclaseactivating polypeptide (PACAP(1-38)) enhances N-methyl-D-aspartate receptor function and brain-derived neurotrophic factor expression via RACK1. J Biol Chem 278:9630-9638. 